\title{
POPIS KAZIVAČA
}

\author{
ALAN $^{1}$ \\ Atalić, Ivanka, Garina, r. Butković, 1921. godine u Alanu \\ Butković, Anka, Matićeva, r. Vukelić, 1922. godine u Rupi \\ Butković, Ivan, Gara, r. 1920. godine u Alanu † \\ Butković, Gašpar, Rila, r. 1941. godine u Alanu \\ Komadina, Mica, Marićeva, r. Tomljanović, 1939. godine u Alanu \\ Rončević, Marija, Garina, r. Butković, 1923. godine u Alanu \\ Tomljanović, Draga, Omanić, r. Tomljanović, 1913. godine u Vrtlini \\ Tomljanović, Ivan, Samardija r. 1944. godine u Zamaliću \\ Tomljanović, Ivka, Marićeva, r. Tomljanović, 1935. godine u Alanu \\ Tomljanović, Jula, Marićeva r. Tomljanović, 1938. godine u Alanu \\ Tomljanović, Mladen, Omanić, r. 1947. godine u Vrtlini \\ Tomljanović, Milan, Periša (Mića), r. 1927. godine u Zamaliću † \\ Tomljanović, Tomislav, Talijan, r. 1937. godine u Zamaliću \\ Vukelić, Ivan, Rokić, r. 1930. godine u Alanu \\ Vukelić, Ivica, Pop, r. 1937. godine u Rupi † \\ Vukelić, Milan, Deviza r. 1959. godine u Senju
}

\section{VELJUN PRIMORSKI ${ }^{2}$}

Krmpotić, Ivica, Šimeta, r. 1947. godine u Veljunu

Krmpotić, Anka, Bokulić, r. Bilen, 1948. godine u Lukovu

Krmpotić, Ante, Šimunov, Škobac, r. 1944. godine u Veljunu

Krmpotić, Ivan, Škobac, r. 1929. godine u Veljunu

Krmpotić, Ivan, Bokula, r. 1948. godine u Veljunu

Krmpotić, Ivan, Šoparin, r. 1925. godine u Veljunu †

Krmpotić, Ivanka, Šimunova, r. Rupčić, 1948. godine u Švici

Krmpotić, Ivka, Grabarova, r. Krmpotić, 1942. godine u Veljunu

Krmpotić, Joso, r. 1942. godine u Veljunu

Krmpotić, Jula, r. Biondić, 1932. godine u Melnici

Krmpotić, Krunoslav, Econja, r. 1936. godine u Melnici

Krmpotić, Luka, Brnde, r. 1919. godine u Veljunu †

Krmpotić, Mara, Brndina, r. Krmpotić, 1922. godine u Milićima

Krmpotić, Marija, Migec, r. 1943. godine u Brinju

Krmpotić, Marica, Migec, r. Smolčić, 1943. godine u Brinju

Krmpotić, Milan, Zekonja, r. 1930. godine u Veljunu

Krmpotić, Milan, Žutija, r. 1931. godine u Veljunu

Krmpotić, Nevenka, Aneličina, Anelica, r. Krmpotić, 1920. godine u Veljunu

1 Naselju Alan pripadaju zaselci: Alan, Brina, Butković Dolac, Cigići, Klanac Alanski, Rupa, Vrtlina, Zamalić (Izvor: KORENČIĆ, Mirko (1979): Naselja i stanovništvo SR Hrvatske: 603-605).

2 Naselju Veljun Primorski pripadaju zaselci: Brezica, Burići, Donji Veljun, Francikovac, Francikovac-Matići, Gornji Veljun, Kuljići, Lopci, Lukci, Marinovići, Milčići, Petrovo, Rončevići, Šabani, Škopci, Veljun Primorski, Zečevi (Izvor: Ibid.). 
Krmpotić, Slavka, r. 1926. godine u Veljunu

Prpić, Anton, Matin, r. 1926. godine u Veljunu

Prpić, Eleonora, Lejina, Hela, r. Krmpotić, 1942. godine u Veljunu

Prpić, Kata, Čopić, r. Krmpotić, 1932. godine u Veljunu

Prpić, Marija, Vinina, r. Krmpotić, 1928. godine u Veljunu

Prpić, Milan, Markin, rođen 1929. godine u Veljunu

Prpić, Milka, Markina, r. Krmpotić, 1931. godine u Veljunu

Tomljanović, Jadranka, Lejina, r. Prpić, 1965. godine u Senju

\section{KRIVI PUT 3}

Filipović, Vlade, r. 1934. godine u Krivom Putu

Prpić, Anka, r. Tomljanović, 1944. godine u Gorici

Prpić, Grgo, Miškec, r. 1939. godine u Krivom Putu

Prpić, Josip, Paljak, r. 1956. godine u Krivom Putu

Prpić, Kata, Domljanova, r. Prpić, 1932. godine u Krivom Putu

Prpić, Ljubica, r. 1945. godine u Vrbanji, Banja Luka

Prpić, Milan, Jonac, r. 1949. u Krivom Putu

Prpić, Nada, Terezina, Bojina, r. Prpić, 1933. godine u Srdarima, S. Brezica

Prpić, Milan, Terezin, r. 1930. godine u Brunićima, Krivi Put

Prpić, Miroslav dr. med, Ropeta, r. 1963. godine u Krivom Putu

Prpić, Mirko, Cungo, r. 1939. godine u Krivom Putu

Prpić, Stjepan, Stipina (Juda), r. 1940. godine u Gorici

Prpić, Tomo, Marojica, r. 1929. Lucići

Prpić, Zdenka, r. Pavelić, 1933. godine u Pavelićima

Špalj, Tome, Cucin, r. 1928. godine u Matićima

Špalj, Ana, r. Špalj, 1926. godine u Špaljima

Špalj, Ana, r. Tomljanović, 1933. godine u Matićima

Špalj, Anka, Jukšina, r. 1933. godine u Špaljima

Špalj, Anton, Franetov, živi u Rijeci.

Špalj, Mile, Kebin, r. 1917. godine u Špaljima $\dagger$

Tomljanović, Branko, Ropeta, r. 1943. godine u Krivom Putu

Tomljanović, Ivan, Tole, r. 1936. godine u Krivom Putu

Tomljanović, Marija, Maca, r. Tomljanović, 1935. godine u Krivom Putu

Tomljanović, Mara, Isanova, r. Krmpotić, 1945. godine u Veljunu

Tomljanović, Zlatko, Pešo, r. 1949. godine u Krivom Putu

Tomljanović, Mila, r. 1945. godine u Špaljima

Tomljanović, Mira Ropetina, r. Prpić, 1931. godine u Lukićima

Tomljanović, Mirko, Sova, r. 1934. godine u Krivom Putu

Tomljanović, Petar, Pešo, r. 1914. godine u Krivom Putu †

Tomljanović, Zlata, Pešina, r. 1923. godine u Krivom Putu

Vukelić, Nena, r. 1940. godine u Krivom Putu

3 Naselju Krivi Put pripadaju zaselci: Anići, Gorica Krivoputska, Krivi Put, Longovac, Nikolići, Šošina, Šojatski Dolac, Špalji, Špinići, Zekanovići; (Izvor: Ibid.). 


\section{PODBILO $^{4}$}

Hotlovec, Katica, r. Prpić, 1925. godine u Matićima

Filipaš Mirpslava, Cotina, Buba r. 1939. godine u Šimerićima, živi u Varaždinu

Pavelić, Marko, Mijatin(a), r. 1917. godine u Žuljevićima

Prpić, Milan, Apel, r. 1960. godine u Matićima

Prpić, Ruža, Apel, r. 1939. godine u Šojatskom Dolcu

Prpić, Marija, Coto, r. Tomljanović, 1931. godine u Podbilu

Prpić, Milan, Juda, r. 1930. godine u Rendulićima

Prpić, Rudolf, (Mijat), Švorac, r. 1924. godine u Lucićima

Šlić, Anka, Tutanova, r. Tomljanović, 1932. godine u Sibinju

Šolić, Petar, Tutan, r. 1924. godine u Krivom Putu

Tomljanović, Ivan, Blitva, Čona, r. 1965. godine u Cupićima

Tomljanović, Jure, Ban, r. 1943. godine u Murtićima

Tomljanović, Gojko, r. 1930. godine u Panjićima

Tomljanović, Milan, Markić, r. 1965. u Žuljevićima

Tomljanović, Petar, Jukša, r. 1935. godine u Matićima

Tomljanović, Petar, Šimaica, r. 1944. godine u Podbilu

Tomljanović, Pere, Rambula, r. 1935. godine u Tomićima

Tomljanović, Petar, Čona, r. 1934. godine u Cupićima $\dagger$

Tomljanović, Marija, Čonina, Tolina, r. Tomljanović, 1930. godine u Panjićima

Tomljanović, Marija, Kikešova, Puljizova, r. 1930. godine u Tomićima

Tomljanović, Marin, r. 1980. godine, u Tomljanovićima

Tomljanović, Marko, Coto, r. 1947. godine u Šimerićima

Tomljanović, Marija, r. Cupić, 1945. godine u Veljunu

Tomljanović, Milan, Ivić, Kanada, r. 1967. godine u Rijeci

Vukelić, Ivan, Mikula, r. 1931. godine u Cupićima

\section{MRZLI DOL}

Blažević, Milan, Ivela, Trečak, Šnajder, Nikolin, r. 1932. godine u Stanić Brigu †

Mihelac, Marija, r. Prpić, 1919. godine u Mrzlom Dolu

Mihelac, Ante, r. 1942. godine u Mrzlom Dolu

Mihelac, Anton, r. 1914. godine u Mrzlom Dolu

Pavelić, Anka, Kuzmanova, r. Lopac, 1936. godine u Vratniku

Pavelić, Ika, Tomina, r. 1925. godine u Pavićima

Pavelić, Kata, Burgija, Medonje, r. 1933. godine u Judić Gorici

Pavelić, Milan, Sikirica, r.1943. godine u Pavićima

Pavelić, Milan, Vranić, r. 1931. godine u Pavićima

Pavelić, Pavla, Ćirilova, r. Krmpotić, 1936. godine u Veljunu

Pavelić, Zdenka, Vranića, r. Burić, r. 1931. godine u Burićima

Prpić, Ana, Matošova, r. u Slunju

Prpić, Anka, Tomljanović, r. 1938. godine u Špaljima

Naselju Podbilo pripadaju zaselci: Cupići, Matić-Gaj, Murtići, Panjići, Plemići, Podbilo, Simerići, Šolići, Tomići, Žuljevići (Izvor: Ibid.).

5 Naselju Mrzli Dol pripadaju zaselci: Katići, Kostići, Lipo Jela, Lučići, Mrzli Dol, Pavelići, Pavići, Rusova Draga, Stanić Breg, Tamburi (Izvor: Ibid.). 
Prpić, Ante, Rus, r.1949. godine u Rusovoj Dragi

Prpić, Dubravka, r. 1941. godine u Mostaru

Prpić, Ivan, Kavarica, r. 1927. godine u Lucićima

Prpić, Josip, Jurina, r. 1928. godine u Rusovoj Dragi

Prpić, Ljubica, r. Platiša, 1916. godine u Platišinoj Dragi

Prpić, Marija, Kavarica, r. Prpić, 1926. godine u Lucićima

Prpić, Marko, Rus, r. 1934. godine u Rusovoj Dragi

Prpić, Milka, r. Klipa, 1936. godine u Plaškom

Prpić, Milan, Matoš, r. 1935. godine u Iličićima

Prpić, Mile, Popić, r. 1938. godine u Popićima

Prpić, Miroslava, Rusova, r. Prpić, u Lucićima

Prpić, Zvonko, Rus, r. 1939. u Rusovoj Dragi

Prpić, Tome, Majorica, r. 1929. godine u Lucićima

Prpić, Marijan, Miladino, r. 1936. godine u Katićima

Tomljanović, Marko, Rilac, r. 1935. godine u Katićima

Tomljanović, Draga, Rilac, r. Margeta, 1937. godine u Stolcu

Tomljanović, Dragica, r. Tomljanović, 1932. godine u Matić Gaju

Tomljanović, Marko r. 1936. godine u Matić Gaju

\section{BUNICA}

Ostović, Mira, Šare, Brzina, r. Tomljanović, 1937. godine u Bunici

Tomljanović, Milan, Livak, r. 1954. u Senju

\section{FRANCIKOVAC}

Prpić, Kata, Čopić, r. Krmpotić, 1932. godine u Veljunu

Prpić, Marija, Nikolčina, r. Tomljanović 1933. godine u Vrataruši

Prpić, Nikola Lopac, rođen 1917. godine u Francikovcu

Prpić, Pere, Nikolčin, r. 1930. godine u Francikovcu

Šojat, Anka Colaševa, r. Butorac, 1948. godine u Dunjevcima, Perušić

Šojat, Milan Colaš, r. 1937. godine u Francikovcu

Šojat, Mladen, Bilin, r. 1928. godine u Francikovcu

\section{SERDARI ${ }^{6}$}

Burić, Kata, r. Grdić, 1930. godine u Rakovici

Pavelić, Ivan, Jandra, r. 1932. godine u Serdarima

Pavelić, Zvonko, Dujela, r. 1938. godine u Serdarima

\section{ŠOJATSKI DOLAC}

Krmpotić, Ivan, r. 1925. godine u Veljunu

Krmpotić, Marija, Marićeva, r. Tomljanović, 1919. godine u Šojatskom Dolcu

Šojat, Ana, Švabina, r. Krmpotić, 1939. godine u Šojatskom Dolcu

Stari naziv: Brezica. 
Šojat, Ante, Tine, r. 1941. godine u Šojatskom Dolcu

Šojat, Francika, Babić, r. Šojat, 1922. godine u Šojatskom Dolcu

Šojat, Ivan, Valin, r. 1935. godine u Šojatskom Dolcu

Šojat, Mara, Budić, r. Prpić, 1931. godine u Judić Gorici

Šojat, Nada, Valina, r. 1939. godine u Šojatskom Dolcu

Šojat, Petar, Budić, r. 1928. godine u Šojatskom Dolcu

Taboga, Mario, Balun, r. 1953. godine u Šojatskom Dolcu

\section{VRATARUŠA}

Tomljanović, Ivan, Rokin, r. 1940. godine u Vrataruši

\section{ŠUŠANJ}

Prpić, Milan, Brkac, r. 1928. godine u Šušnju

\section{KOSOVA BULJIMA}

Prpić, Nada, Grga(j)ica, r. Prpić, 1939. godine u Kosova Buljimi

\section{SV. JELENA}

Špalj, Milan, Škicin, r. 1937. u Donjim Špaljima

\section{VIROVITICA}

Vladimir Prpić Matić, Jukin, rođen 1936. godine u Podgorju (druga generacija migranata)

Josip Prpić Matić, Jukin, rođen 1967. godine u Podgorju (treća generacija migranata)

Oliver Krmpotić Vuča, rođen 1973. godine u Podgorju

Drago Cah, rođen 1952. godine u Podgorju

Vladimir Pavelić Kuzman, rođen 1952. godine u Virovitici

Josip Pavelić Zozan, živi u Krčevinama (druga generacija migranata)

Jela Pavelić Zozanova, živi u Krčevinama (druga generacija migranata)

Željko Tomljanović Rilac, rođen 1950. godine u Podgorju (prva generacija migranata)

Dinko Filipović Vicinov, rođen 1954. godine u Podgorju (prva generacija migranata)

Ivan Filipović Vicinov, r. 1924. godine u Krmpotama (doselio u Viroviticu u ranom djetinjstvu) 